\title{
Diagnosis and Therapeutic Management of Babesia gibsoni Infection in Dog
}

\author{
C. K. Ghosh ${ }^{1}$, M. Mondal ${ }^{1 *}$, F. Mridha ${ }^{1}$, S.S. Kesh ${ }^{1}$, P. Sarkar ${ }^{2}$, \\ A. Maity ${ }^{3}$ P. Mukherjee ${ }^{1}$ and D. Mandal ${ }^{2}$
}

${ }^{1}$ Department of Veterinary Clinical Complex, ${ }^{2}$ Department of Veterinary Gynaecology and Obstetrics, ${ }^{3}$ Department of Veterinary Biochemistry, West Bengal University of Animal and Fishery Sciences, Kolkata, India

*Corresponding author

\section{A B S T R A C T}

\section{Keywords}

Babesia gibsoni, Dog, Haemato biochemical alteration,

Therapeutic management

\section{Article Info}

Accepted:

24 July 2020

Available Online:

10 August 2020
A 5 years old male Rottweiler was presented to Veterinary Clinical Complex, Faculty of Veterinary and Animal Sciences, West Bengal University of Animal \& Fishery Sciences, Kolkata with clinical signs of high-rise of temperature $\left(105^{\circ} \mathrm{F}\right)$, anorexia, extreme dullness, nausea, and disinclination to move. Affected dog had elevated heart rate (158 per minute) and respiration rate (57 per minute). Blood smear examination revealed that dog was positive for Babesia gibsoni. Present communication revealed haematobiochemical alterations comprised of hypohaemoglobinaemia, erythrocytopaenia, thrombocytopaenia, leucocytosis, elevated aminotransferase activities, BUN, creatinine, bilirubin and hypoglycaemia. The dog was treated with two consecutive doses of Imidocarb dipropionate at 14 days interval in combination with fluid therapy, doxycycline and hematinic for 21 days. Complete follow up of the case exhibited successful clinical recovery of the dog within three weeks.

\section{Introduction}

Canine babesiosis is a life threatening haemoprotozoan disease mainly caused by Babesia canis or Babesia gibsoni. Amongst the various prevalent canine vector borne diseases, babesiosis is a common disease caused by intra-erythrocyte protozoa $B$. gibsoni is a small piroplasm $(1.0-2.5 \mu \mathrm{m})$, that occurs as a single ring form or pyriform bodies within the erythrocyte (Conrad et al., 1991; Birkenheuer et al., 1999). Dogs get infection when they are inoculated with sporozoites of $B$. gibsoni present in tick saliva. After inoculation, Babesia sporozoites invade erythrocytes where they multiply 
asexually by binary fission and the resultant merozoites rupture the red blood cell and go on to invade additional erythrocytes. Babesia gibsoni is generally transmitted by Rhipicephalus sanguineus, the brown dog tick. Dogs with babesiosis often present with moderate to severe haemolytic anaemia, hyperbilirubinuria, splenomegaly, coagulopathies, multiple organ dysfunction syndrome and clinical illness characterized by fever, anorexia, depression, pallor, icterus, vomition, hemoglobinuria, bounding pulse etc. (Vial and Gorenflot, 2006; Gonde et al., 2016). The severity of babesiosis depends on the extent of parasite replication in the host's erythrocytes with subsequent lyses of cells. Affected dog revealed a wide variation of clinical signs like depression, anorexia, fever, haemolytic anaemia, icterus, vomition and marked deterioration of body condition accompanied by variable clinicopathological abnormalities including ascites, haemoglobinuria, hypoglycemia, acid-base disturbances, azotemia and elevated aminotransferase activities (Irwin, 2010; Gonde et al., 2016). The present communication has reported about canine babesiosis caused by an emerging pathogen Babesia gibsoni and its therapeutic management.

\section{History and observations}

A 5 years old male Rottweiler was presented to Veterinary Clinical Complex, Faculty of Veterinary and Animal Sciences, West Bengal University of Animal \& Fishery Sciences, Kolkata with clinical signs of highrise of temperature, anorexia, depression and nausea. Physical examination of the dog had findings like extreme dullness and disinclination to move. The dog had history of tick infestation two weeks ago.

Affected dog exhibited clinical parameters comprised of pale visible mucous membrane of conjunctiva and buccal cavity, elevated rectal temperature $\left(105.4^{0} \mathrm{~F}\right)$, heart rate (147/minute), respiration rate (49/minute). Representative sample of blood was collected for haemato-biochemical alteration and demonstration of haemoprotozoa microscopically. Peripheral blood smear stained with Giemsa detected trophozoites of small form (Babesia gibsoni) (Fig. 1). Affected dog had hypohaemoglobinaemia, erythrocytopaenia, thrombocytopaenia, leucocytosis, increased activity of alanine aminotransferase (ALT) and alkaline phosphatase (ALP), elevated level of BUN, creatinine, bilirubin and hypoglycaemia (Table 1). Blood samples were taken on day 0 and 22 for haemato-biochemical and parasitological examination.

\section{Discussion and therapeutic management}

Hypohaemoglobinaemia and erythrocytopaenia and thrombocytopaenia in the present study have indicated haemolytic anaemia in canine babesiosis. Affected dog revealed leukocytosis because of toxins produced by the parasites. Present communication exhibited elevated level of bilirubin, increased activity of ALT and ALP, and higher level of creatinine indicative of liver stress that might be due to inflammatory cytokines, or hypoxic damage (Gonde et al., 2016). Hypoglycemia in canine babesiosis was also reported by earlier worker (Schoeman, 2009). Depending on the clinical signs, haemato-biochemical status and blood smear examination, the dog was treated with Inj. Dextrose 5\%@250 ml intravenously for 5 days, Inj. Imizet ${ }^{R}$ (Imidocarb dipropionate) @ $6 \mathrm{mg} / \mathrm{kg}$ body weight subcutaneously for two doses at 14 days interval, Inj. Atropine sulphate @ 0.04 $\mathrm{mg} / \mathrm{kg}$ body weight subcutaneously, 15 minutes prior to Imidocarb administration. Tab. Dr Doxy (doxycycline) @ $10 \mathrm{mg} / \mathrm{kg}$ body weight/day was given orally for 21 days. 
Table.1 Haematobiochemical alterations in the infected dog on day 0 and day 22

\begin{tabular}{|c|c|c|c|c|}
\hline \multicolumn{2}{|c|}{ Parameters } & Value in day 0 & Reference range & Value in day 22 \\
\hline \multicolumn{2}{|c|}{$\mathrm{Hb}(\mathrm{g} / \mathrm{dl})$} & 9.8 & $12-18$ & 11.4 \\
\hline \multicolumn{2}{|c|}{ TEC $\left(\times 10^{6} / \mu \mathrm{L}\right)$} & 3.9 & $5.8-8.9$ & 5.6 \\
\hline \multicolumn{2}{|c|}{$\operatorname{TLC}(\mathbf{X 1 0} / \mu \mathrm{L})$} & 13.6 & $6-15$ & 17.2 \\
\hline \multirow[t]{5}{*}{ DLC } & Neutrophil(\%) & 69 & $55-80$ & 65.6 \\
\hline & Monocyte(\%) & 3.2 & $2-6$ & 2.7 \\
\hline & Lymphocyte(\%) & 32 & $15-30$ & 22.4 \\
\hline & Basophil(\%) & 0 & $0-1$ & 1.8 \\
\hline & Eosinophil(\%) & 2.8 & $2-8$ & 2.2 \\
\hline \multicolumn{2}{|c|}{ Platelets $\left(10^{3} / \mu \mathrm{L}\right)$} & 150 & $177-398$ & 192 \\
\hline \multicolumn{2}{|c|}{$\operatorname{PCV}(\%)$} & 30.8 & $37-55$ & 41 \\
\hline \multicolumn{2}{|c|}{ Blood Glucose (mg/dl) } & 85.8 & $65-112$ & 102.4 \\
\hline \multicolumn{2}{|c|}{ SGPT/ALT(U/L) } & 86.6 & $10-80$ & 20.7 \\
\hline \multicolumn{2}{|c|}{ SGOT/AST (U/L) } & 92.2 & $10-75$ & 38.6 \\
\hline \multicolumn{2}{|c|}{$\operatorname{ALP}(\mathbf{U} / \mathbf{L})$} & 193.2 & $20-155$ & 104.6 \\
\hline \multicolumn{2}{|c|}{ Total bilirubin (mg/dl) } & 1.2 & $0.3-0.9$ & 0.8 \\
\hline \multicolumn{2}{|c|}{$\begin{array}{l}\text { Conjugated bilirubin } \\
\text { (mg/dl) }\end{array}$} & 0.7 & $>0.3$ & 0.3 \\
\hline \multicolumn{2}{|c|}{$\begin{array}{l}\text { Serum urea } \\
\text { nitrogen }(\mathbf{m g} / \mathbf{d l})\end{array}$} & 79.7 & $7-25$ & 18.2 \\
\hline \multicolumn{2}{|c|}{ Creatinine(mg/dl) } & 2.8 & $0.7-1.8$ & 1.02 \\
\hline \multicolumn{2}{|c|}{ Total protein(gm/dl) } & 7.8 & $5.4-7.1$ & 6.8 \\
\hline \multicolumn{2}{|c|}{$\operatorname{Albumin}(\mathrm{gm} / \mathrm{dl})$} & 3.2 & $2.5-3.7$ & 3.04 \\
\hline \multicolumn{2}{|c|}{ Globulin(gm/dl) } & 4.6 & $2.4-4$ & 3.7 \\
\hline
\end{tabular}

Fig.1 Small circular trophozoites of Babesia gibsoniin erythrocytes of the infected dog

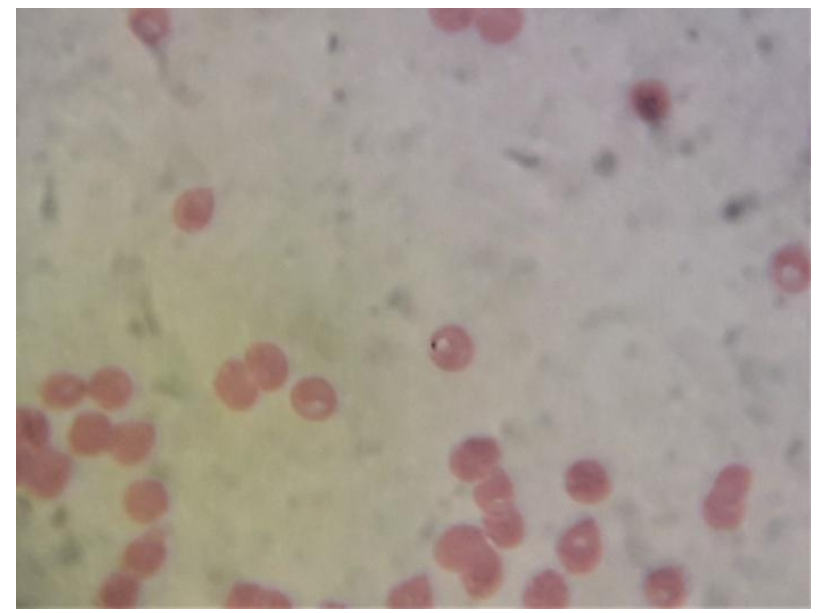



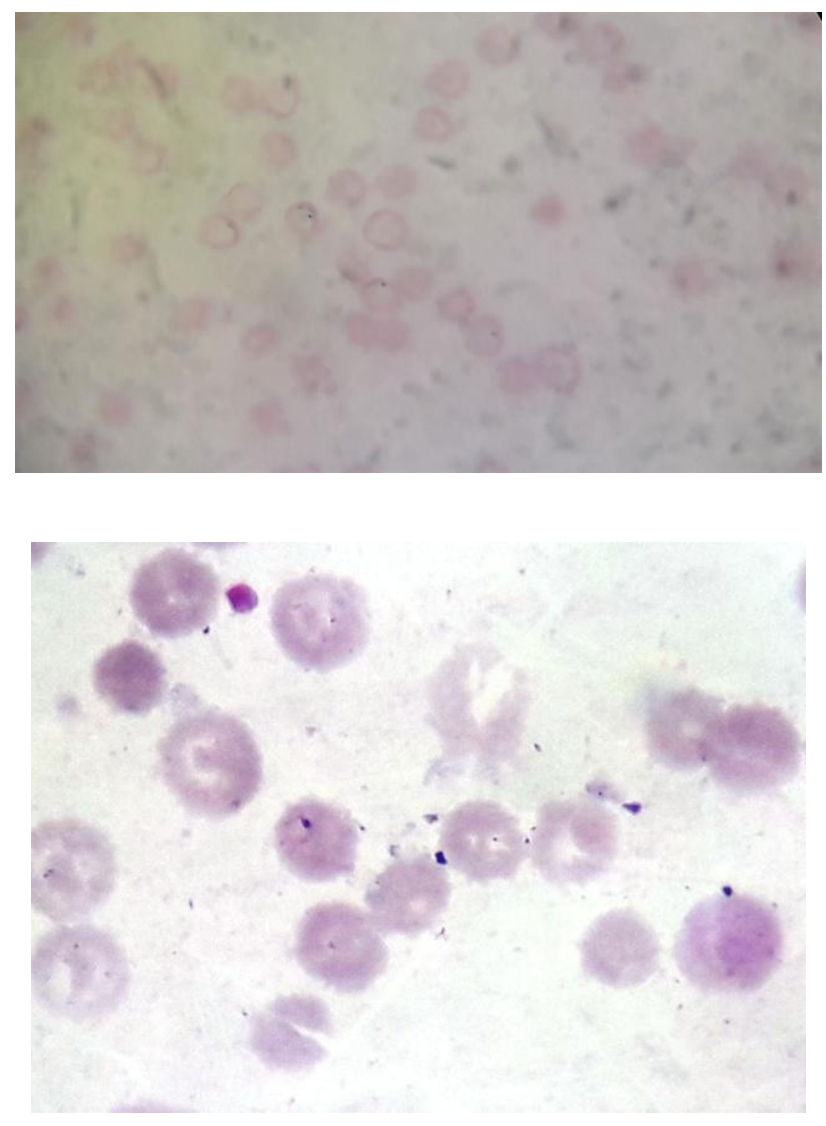

Oral hematinic (Syrup aRBC pet ${ }^{\mathrm{R}}$ ) @ 1 teaspoonful twice daily was administered orally daily for 21 days.

Imidocarb and clindamycin are two most commonly used babesiacides used worldwide (Bhojne et al., 2013). As the Babesia sp destroys RBC, causes anaemic anoxia (Irwin, 2010), effective management in an acute emergency involves supportive therapy also like restoring adequate tissue oxygenation and correction of severe anaemia by oxygen support and whole blood transfusion. The follow up of the present case was carried out on day 22. At day 22, peripheral blood smear with Giemsa stain showed negative for Babesia gibsoni. Haemato-biochemical parameters were improved significantly. Complete clinical recovery was observed and the dog exhibited remarkable response and uneventful recovery. The owner was advised to continue the hematinics for another one month.

\section{References}

Bhojne, G.R., Dakshinkar, N.P., Sanghai, A.A. and Dubey, A.G. (2013). Canine Babesiosis-A Case Study. Indian Journal of Canine Practice, 5(1): 117118.

Birkenheuer, A.J., Levy, M.G., Savary, K.C.M., Gager, R.B. and Breitschwerdt, E.B. (1999). Babesia gibsoni infections in dogs from North Carolina. Journal of the American Animal Hospital Association, 35(2): 125-128.

Conrad, P.A., Thomford, J. and Yamane, I. (1991). 'Hemolytic anemia caused by Babesia gibsoni infection in dogs'. Journal of the American Veterinary Medical Association, 199(5): 601-605. 
Gonde S., Chhabra, S., Uppal, S.K., Singla, L.D. and Randhawa, S.S. (2016). A unique case of Babesia gibsoni infected dog with paraplegia. Journal of Parasitic Diseases, 40(4): 1605-1608.

Irwin, P.J. (2010). Canine Babesiosis. Vet. Clin. Small Animal, 40: 1141-1156.
Schoeman, J.P. (2009). Companion animal clinical studies. Onderstepoort J. Vet. Res., 76: 59-66.

Vial, H.J. and Gorenflot, A. (2006). Chemotherapy against babesiosis. Veterinary Parasitology, 138:147-160.

\section{How to cite this article:}

Ghosh, C.K., M. Mondal, F. Mridha, S.S. Kesh, P. Sarkar, A. Maity, P. Mukherjee and Mandal, D. 2020. Diagnosis and Therapeutic Management of Babesia gibsoni Infection in Dog. Int.J.Curr.Microbiol.App.Sci. 9(08): 3275-3279. doi: https://doi.org/10.20546/ijcmas.2020.908.374 